\title{
Minnesota bog study turns up the heat on peat
}

\section{Experiment boosts temperature and carbon dioxide to gauge global-warming response.}

\section{BY ALEXANDRA WITZE}

$\mathrm{I}$ n a peat bog in northern Minnesota, researchers have built a little patch of the future.

Ten octagonal enclosures - each 12 metres across, 8 metres high and open to the sky dot the US Forest Service's Marcell Experimental Forest. Boardwalks wend their way around them, allowing scientists to walk above a pristine 8.1-hectare peat bog and get a close-up peek at Earth's greenhouse fate.

Half of the enclosures have carbon dioxide gas wafting into them at concentrations of 900 parts per million - more than twice that of today's atmosphere. Hot-air blowers and soil heaters raise temperatures by up to $9^{\circ} \mathrm{C}$ above that of the outside air. The combination of warmth and elevated $\mathrm{CO}_{2}$ places this study in a wave of experiments that are probing how some of Earth's most sensitive ecosystems — in this case, carbon-rich peatlands - will respond to climate change.

The US Department of Energy and the Forest Service were this week set to formally kick off the full US\$10.5-million experiment, called Spruce and Peatland Responses Under

"It allows us to
cheat today's
conditions
and take on
the whole
ecosystem."

Climatic and Environ-

mental Change (SPRUCE). The study is planned to run for a decade.

"We think this gives us a good glimpse as to what future climates might look like," says Paul Hanson, an ecologist at Oak Ridge National Laboratory in Tennessee and the experiment's project coordinator. "It allows us to cheat today's conditions and take on the whole ecosystem, from the top of the trees to the deep peat."

Previous experiments have typically raised either $\mathrm{CO}_{2}$ levels or temperatures in small sample plots of ecosystems, such as temperate and tropical forests. SPRUCE is rare in using both elevated $\mathrm{CO}_{2}$ and heating on a large scale, and in warming the soil to 2 metres' depth.

Although they cover just 3\% of Earth's surface, peatlands contain roughly onethird of the planet's terrestrial carbon stores. As temperatures rise, bogs are expected to release more carbon, contributing to even

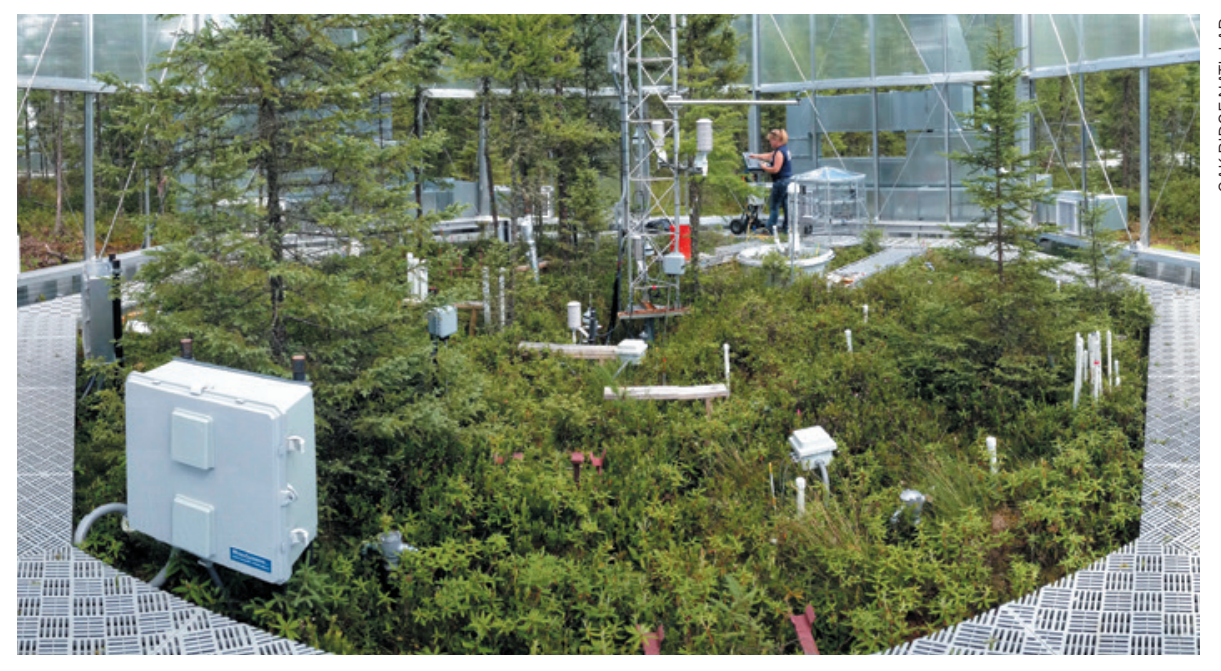

Study enclosures will be monitored continuously over a decade.

greater warming. But computer models of future climate do not accurately account for peatland carbon emissions, Hanson says. In the SPRUCE experiment, scientists do not yet know whether that carbon release will come mostly in the form of $\mathrm{CO}_{2}$ or as the more potent heat-trapping gas methane. Although bogs release mainly $\mathrm{CO}_{2}$ today, methane could become the primary greenhouse gas produced by the SPRUCE bog as it warms - as long as the peat stays wet. If it dries out, the types of microbe living in the peat may shift and begin putting out more $\mathrm{CO}_{2}$ again.

"Experiments like SPRUCE not only let us test what we think we know - often they surprise us by showing us what we don't," says Susan Trumbore, a biogeochemist at the Max Planck Institute for Biogeochemistry in Jena, Germany.

\section{HOT PLATES}

In June 2014, SPRUCE technicians flipped a switch to turn on resistance heaters that penetrate the peat bog in concentric circles. As a result, 2 metres down, carbon-rich decaying moss that dates back $4,000-7,000$ years is now being heated to as much as $9^{\circ} \mathrm{C}$ above the temperature of the outside air. The experiment's air heaters were switched on in mid-August.

Researchers have already seen hints of how the peat responds to warming. Water flowing through the bog, for instance, has not changed much chemically in the past year, says Natalie
Griffiths, an aquatic biogeochemist from Oak Ridge who presented the findings this month at a meeting of the Ecological Society of America. That suggests the peat may be fairly resistant to warming, she says - at least at the start. Long-term studies will include tests of whether soil microbes - and their roles in the ecosystem - change as temperatures rise.

What SPRUCE finds in this northern boreal forest should inform permafrost-warming studies that the US Department of Energy and others have been carrying out across the Arctic. More broadly, SPRUCE could unite with other soil experiments in an international network that would exchange results. Hanson has joined Margaret Torn of California’s Lawrence Berkeley National Laboratory and others in calling for an international link-up to share data on how soils might respond to changing climate (M. S. Torn et al. SOIL 1, 575-582; 2015).

Despite its goals, SPRUCE itself has a sizeable carbon footprint. The electricity bill soars to more than $\$ 1,000$ a month in the summer, and the experiment will be even more costly to run through the cold Minnesota winter. If ambient temperatures fall low enough to about $-26^{\circ} \mathrm{C}-$ the propane gas running through the heating pipes will no longer be able to maintain the necessary warmth. "We're planning to run year-round," says Hanson, "unless it's so cold the engineering portion of the system can't keep up." - 